\title{
Integrated sustainability for transportation infrastructure development in Indonesia: A case study of Karawang region
}

\author{
Ayomi Dita Rarasati ${ }^{1,2, *}$, and Tamara R.F. Iskandar ${ }^{1,2}$ \\ ${ }^{1}$ Civil Engineering Department, Faculty of Engineering, Universitas Indonesia, Indonesia \\ ${ }^{2}$ Center for Sustainable Infrastructure Development, Faculty of Engineering, Universitas Indonesia, \\ Indonesia
}

\begin{abstract}
Efficient infrastructure provides social and economic benefits to the society and there is a need to develop a modern infrastructure in order to ensure the well-being of the society to make a sustainable social, economic and environmental growth. However, costs always become the impeding factor for stakeholders when they contemplate sustainability initiatives. Therefore, it is crucial to balance the financial benefits with sustainability deliverables in transportation infrastructure development. This research aims to develop feasibility of implementation from an environmental, social, and economic sustainability perspective in comprehensive integrated infrastructure development. The results show that safety is the most influencing factors in selecting mode of transportation, more reliable service is needed to be improved to attract public transportation users and security is needed to enhance transportation facility to promote public transportation use.
\end{abstract}

\section{Introduction}

Efficient infrastructure provides social and economic benefits to the society. Furthermore, there is a need to develop a modern infrastructure in order to ensure the well-being of the society to make a sustainable social, economic and environmental growth. Sustainable development is about making societal investments that are sensitive to the natural environment and at the same time financially viable in the long term [1]. The choice to implement sustainable infrastructure, however, faces major obstructions for environmental sustainability. Sustainable infrastructure development requires drastic change in culture and behaviour of the society, but also needs to be incorporated in its underlying policies as well [2]. Additionally, although the application of sustainability in built assets is beneficial, it often involves major capital investment. Costs always become the impeding factor for stakeholders when they contemplate sustainability initiatives. Therefore, it is crucial to balance the financial benefits with sustainability deliverables in transportation infrastructure development.

\footnotetext{
*Corresponding author: ayomi@eng.ui.ac.id
} 
The concern of current and future transportation development system originated from the lack of integration and interaction between the transportation system and the environment. Although infrastructure is crucial in modern economy, more infrastructures may not necessarily mean more growth. The issue with infrastructure expansion often comes at the expense of the local environment [3]. The realization that environmental quality has been affected tremendously by transportation activities, which continue to accumulate over time, aroused the concern of many people that the transportation development that has been carried out so far was a mistake in terms of policy making and planning [4]. Past and current practice of transportation infrastructure, both from the society and from the government, needs to shift forward and should be seen from a different perspective if improved quality of life wants to be achieved.

The success of regional development and the state is determined by the availability of natural resources, human resources and facilities and other supporting infrastructure. One of the contributing factors of successful development is the availability of infrastructure that aims to support the mobility of resources and facilitate the implementation of sustainable development. That is why infrastructure became one of the main priorities in the government's development plans because it generates a multiplier effect. A number of potential benefits hoped to be achieved from these development plans in construction of roads and the transport sector in general, among others: changes in the relative cost of new transportation means to transport long; increased availability of means of transportation; improved ride quality; increased economic activity that ultimately affect change people's consumption patterns and structures; the increase in per capita income of the people, and so forth. However, the existing conditions of the transportation infrastructure in Indonesia suffers issues particularly in having gaps between provinces, issues in developing the facilities, funding limitations in the transportation sector and many other issues regarding its development [5].

In accordance with the accelerated growth of the global community to eradicate poverty and tackle climate change, growth strategies still seem to fail to be proven sustainable. A common impetus that could provide the necessary initiative against the challenging obstruction is infrastructure development. A sustainable infrastructure will cut down unnecessary costs, lost production costs, as well as decrease energy consumption, waste and pollution.

The servicing and provision of Indonesia's infrastructure is not optimum and there are huge inconsistencies in achievement between different regencies/cities. This can be seen from the limited provision of infrastructure and less infrastructure network in areas outside Java Island. Java Island is a huge boost to Indonesia's economy, measuring up to $80 \%$ of its income. This integrated transportation system hopes to accelerate the rate of economic growth in Indonesia. In terms of infrastructure network, Java Island is the most developed where nearly all major provinces scored top 10 in the mapping of infrastructure in Indonesia [2]. However, effectiveness of sustainable infrastructure may also vary depending on the related party's ability to take advantage of the situation, in addition to other constraints such as poor managerial incentives, planning, externalities from missing components, as well as inefficient and unintegrated transportation system [3].

Therefore, this research aims to determine demands and conditions by Indonesian citizens, as well as to investigate financial constraints of sustainability measures and develop feasibility of implementation from an environmental, social, and economic perspective in comprehensive integrated infrastructure development in Karawang region in Indonesia, with a particular focus in transportation system. However, this paper will only discuss the critical demands and conditions according to Indonesian citizens in pursuing integrated urban transportation development based on transportation sustainability indicators in Karawang region in Indonesia. 


\section{Sustainable transportation indicators}

There are three aspects of sustainable transport, namely sustainability in environmental, social, and economy. The goal of sustainable development is the creation of an equal balance between the economic, environmental, social, and governance aspects, in order to create more liveable and productive cities, towns, and villages by using methods that require the participation of decision makers and stakeholders and new tools to enable decision makers to respond properly [6]. Hence, sustainable development requires the effective participation and initiative of stakeholders, including governments, industry, academia, and society as the basis of its efforts to achieve a balanced development.

Sustainable infrastructure can be defined as an infrastructure which integrates these three key components in accordance with governance aspects into a project's planning, building and operating phases [7]. A sustainable infrastructure should also ensure resilience towards climate changes or shocks in order to improve the attractiveness of infrastructure investments by mitigating risks, creating tangible benefits and opportunities as well as reducing emissions and climate risks [8].

Socially sustainable infrastructure means that it inclusive and respects human rights. This includes meeting the needs of the poor by increasing infrastructure access, supporting general poverty and inequality reduction, and reducing vulnerability to climate change risks. Socially sustainable transport is a transport that can minimize the extent of accidents, and can enhance social justice and the level of health in the community. Therefore, in the social aspect, sustainable transport is defined as a transport system which is capable of creating equality towards every aspect against the use of transport itself, with high transportation safety levels, where the institutional system is capable of supporting the creation of a sustainable transportation system [9].

Economically sustainable infrastructure means that it positively impacts Gross Domestic Product (GDP) per capita and job outcomes. It does not burden governments with debt they cannot repay, or end-users - especially the poor-with tariffs they cannot afford. Furthermore, sustainable transportation in economic aspect is transportation that is affordable, operates efficiently, can provide alternative modes of transport, where it improves accessibility and supports the economic growth rate. This relates to the purpose of the transport sector which is to support the economic development of the region [9].

Environmentally sustainable infrastructure means that it establishes the foundation for a transition to a low-carbon economy, leaves a low-carbon footprint, and is also resilient to climate change. Environmentally sustainable transport among others is a transportation which minimizes air pollution, noise level, and the level of use of resources that are not renewable, in order to minimize public health impacts related to transport activities. A sustainable infrastructure can also employ fundamentally different ways of meeting infrastructure service needs, including the implementation of more responsive and integrated information systems that complement its hard infrastructure [9].

Sustainability indicators are selected, targeted, and compressed variables that reflect public concerns and are of use for the decision maker [10]. Indicators of sustainable development had been discussed at an international level, but what is at issue is how to apply it at the national level and even further at an urban level (city/county), as there is difference in focus between the national and local levels as well as the differences between the regions. In terms of sustainability indicators, many institutions have had defined their own standards and measures for this particular matter. Sustainability is generally evaluated using indicators, which are specific variables suitable for quantification or measurement. Such indicators are useful for identifying trends, predicting problems, setting targets, evaluating solutions and measuring progress. Which indicators are selected can significantly influence analysis results. A particular policy may seem beneficial and 
desirable if evaluated using one set of indicators but harmful and undesirable according to others. It is therefore important that people involved in sustainability planning understand the assumptions and perspectives of the performance indicators they apply.

\section{Research methodologies}

The research is positioned as mixed methods research that uses complementary primary data collection and secondary data collection that are computed using quantitative method. The research began with a quantitative phase, which is a survey as a primary source of data for the research. A review of the literature was undertaken to help establish a rationale for the research questions and to establish the extent and depth of existing knowledge on sustainable transportation indicators where it can be further assessed according to the development of current transportation system in Indonesia, as well as to determine the critical demands of pursuing sustainability in transportation in a certain area that serves as a benchmark for the research.

This research used questionnaire-based surveys as the method to identify the critical demands of the Indonesian community that emphasizes in pursuing a sustainable transportation system by bench-marking on a village in Indonesia, as well as to analyze the feasibility of the demands in a benefit cost ratio analysis towards the sustainable transportation indicators that are proposed. The questionnaire surveys were selected for the reason that questionnaire surveys are effective in gathering information about the characteristics, actions, or opinions of a large group of people [8]. In the questionnaire survey, Indonesian citizens (namely those who are 15 to 64 years of age) were asked to rate their demands and conditions in transportation development referring to the proposed sustainable transportation indicators, and were also asked about their availability in participating in the transportation development process itself.

Prior to the distribution of questionnaires to the respondents, a survey was initially piloted to a small sample of respondents. In addition, the pilot survey was also tested for its validity, using the Pearson-Product Moment Correlation, and reliability, with the Spearman-Brown Prophecy Formula and Cronbach's Alpha. Data collected from the questionnaire surveys are recorded and analyzed using a software program. Following the data collection, data analysis is done through a quantitative approach by quantification of the qualitative data into statistical analysis. Furthermore, data analysis is best used through the aid of software programs [12].

\section{Results}

A total of 500 questionnaires were prepared for the respondents with a cover letter from the Civil Engineering Department, Universitas Indonesia. The survey was administered throughout March - April 2017. Respondents that participated in this research come from various gender, age, education and occupational background to achieve heterogeneity of the data collected. Furthermore, respondents are also acquired in different locations in the Karawang region (i.e. north/beach area, south/mountain area, and centre/city area of Karawang). Out of the 500 questionnaires, the researchers managed to obtain a total of 344 questionnaires through questionnaire distribution and structured interview.

Following the employed mixed methods research of questionnaire survey and structured interview, the results were processed using the validity and reliability test. For the validity test, a significance level of $0.05(5 \%)$, confidence level of $95 \%$, with the degree of freedom (df) of 342 was determined from the data collection. Furthermore, a one-way tailed test with an r-table value of 0.089 was employed as the hypothesis used in the research consists 
of only one possibility. The r-table values of the validity test were compared with the $r$ value computed from the research where all statements are proven to be $100 \%$ valid as all $r$ values exceed the r-table values from the validity test.

Moreover, the type of reliability test that was used is the internal consistency reliability type, with the split-halves method using the Spearman-Brown Prophecy formula and Cronbach's Alpha. After computation of the data, the reliability test value for the splithalves method of the research is 0.94 , which means according to the Spearman-Brown Prophecy Formula, the test would imply that it is approximately $94 \%$ reliable as it is true and yields consistent results of the same measure. Additionally, if calculated using the Cronbach's Alpha method, the reliability test value would yield 0.895 or essentially 0.9 if rounded up. This would suggest that if compared to the Internal Consistency Cronbach's Alpha table $(\alpha \geq 0.9)$, the test is considered within the 'excellent' grade. Thereupon, as the outcome of the survey passed both the validity and reliability test, the research can then be further processed for data computation.

The administered mixed methods of questionnaire survey and structured interviews consisted of questions, each with a specific purpose of answering the research questions. Therefore, the findings of the data are framed around the components that will satisfy the aims and objectives of this study while synthesizing the need to address the research questions. The mixed methods focused on the basis of the identification of critical demands and needs of transportation in Karawang related to sustainable measures. The respondents were asked to indicate the extent of importance, agreements, and willingness of statements specified in the questionnaire survey on a four-point Likert rating scale.

Furthermore, the results are set out where the highest and lowest earning rates are highlighted for ease of data illustration. The highest earning rates are highlighted in light grey, whereas the lowest earning rates are highlighted in dark grey. As the survey was conducted at three locations - the city, mountain area, and beach area - the data are illustrated according to their locations as well, aside from the overall score of all locations.

Table 1 summarizes data for question on 'how certain factors may affect the respondents' choice of public transportation'. Overall, the respondents agree that 'safety' is the most crucial factor that affects their transportation choice with $8.83 \%$. This is also true for respondents that are from the city and beach area. However, respondents from the mountain area imply that the most crucial factor is 'security', where 'safety' is in fact third in place after 'health benefits'. 'Weather' seems to be the most undecided factor that affects transportation choice, with the overall score of the respondents, as well as respondents residing in mountains and city area agreeing to the statement. In contrast, respondents residing in the beach area suggest that 'environmental concerns' as well as 'social stigma' as the most undecided factor for transportation choice, where 'weather' ranks third out of the thirteen statements.

Table 2 summarizes results for question on 'what factors should be improved in transportation to attract more public transportation users'. Overall, the respondents agree that a 'more reliable service' should be improved to attract more transportation users with $11.06 \%$, where the lowest factor would be 'public commercial' with $8.86 \%$. If divided to each location, city respondents suggest that they agree with the overall consensus for both highest and lowest factor in attracting more transportation users. However, data from mountain respondents imply that a 'cheaper fare' would attract more transportation users with $10.96 \%$ compared with $10.80 \%$ for a 'more reliable service', where the lowest factor is 'integration with other modes' and 'less environmental impact'. Additionally, respondents residing in and around the beach area suggest that 'better transportation facilities' as the most crucial factor with $11.16 \%$, where the lowest factor is 'less environmental impact' with $8.37 \%$. 
Table 1. Factors influence in selecting mode of transportation.

\begin{tabular}{|c|c|c|c|c|}
\hline \multirow{2}{*}{$\begin{array}{c}\text { Does the following factor affect } \\
\text { your choice of transportation? }\end{array}$} & \multicolumn{3}{|c|}{ Rate in Percentage } \\
\cline { 2 - 5 } & Overall & City & Mountain & Beach \\
\hline Affordability & $7.13 \%$ & $7.02 \%$ & $7.46 \%$ & $8.16 \%$ \\
\hline Weather & $6.88 \%$ & $6.80 \%$ & $7.15 \%$ & $7.58 \%$ \\
\hline Frequency of service & $7.38 \%$ & $7.29 \%$ & $7.61 \%$ & $8.16 \%$ \\
\hline Environmental concerns & $7.18 \%$ & $6.82 \%$ & $7.31 \%$ & $6.41 \%$ \\
\hline Convenience & $8.07 \%$ & $8.09 \%$ & $7.91 \%$ & $8.16 \%$ \\
\hline Personal comfort & $8.48 \%$ & $8.56 \%$ & $7.91 \%$ & $8.45 \%$ \\
\hline Safety & $8.83 \%$ & $8.98 \%$ & $7.91 \%$ & $8.45 \%$ \\
\hline Social stigma & $7.44 \%$ & $7.51 \%$ & $7.46 \%$ & $6.41 \%$ \\
\hline Distance to nearest stop/station & $7.33 \%$ & $7.25 \%$ & $7.76 \%$ & $7.58 \%$ \\
\hline Travel time & $7.77 \%$ & $7.77 \%$ & $7.61 \%$ & $8.16 \%$ \\
\hline Health benefits & $7.76 \%$ & $7.79 \%$ & $8.07 \%$ & $6.71 \%$ \\
\hline Reliability & $7.51 \%$ & $7.51 \%$ & $7.46 \%$ & $7.58 \%$ \\
\hline Security & $8.57 \%$ & $8.62 \%$ & $8.37 \%$ & $8.16 \%$ \\
\hline
\end{tabular}

Table 2. The need of transportation improvement to attract public transportation users.

\begin{tabular}{|c|c|c|c|c|}
\hline \multirow{2}{*}{$\begin{array}{c}\text { Transportation improvement in } \\
\text { the following factors will attract } \\
\text { more public transportation users }\end{array}$} & \multicolumn{4}{|c|}{ Rate in Percentage } \\
\cline { 2 - 5 } & Overall & City & Mountain & Beach \\
\hline More public transportation routes & $9.93 \%$ & $9.84 \%$ & $9.97 \%$ & $10.36 \%$ \\
\hline Increased frequency of armada & $10.12 \%$ & $10.09 \%$ & $10.30 \%$ & $9.16 \%$ \\
\hline Better path/road condition & $10.87 \%$ & $10.83 \%$ & $10.63 \%$ & $11.16 \%$ \\
\hline Better transportation facilities & $10.95 \%$ & $10.95 \%$ & $10.47 \%$ & $11.16 \%$ \\
\hline Cheaper fares & $10.85 \%$ & $10.78 \%$ & $10.96 \%$ & $10.76 \%$ \\
\hline More reliable service & $11.06 \%$ & $11.13 \%$ & $10.80 \%$ & $9.56 \%$ \\
\hline Integration with other transportation & $8.96 \%$ & $8.92 \%$ & $9.14 \%$ & $9.56 \%$ \\
\hline modes & $9.17 \%$ & $9.15 \%$ & $9.14 \%$ & $8.37 \%$ \\
\hline Acess environmental impacts & $9.32 \%$ & $9.41 \%$ & $9.30 \%$ & $10.36 \%$ \\
\hline Access to transportation mode & $8.86 \%$ & $8.90 \%$ & $9.30 \%$ & $9.56 \%$ \\
\hline Public commercial & & &
\end{tabular}


Table 3. The need of transportation facility improvement to promote public transportation use.

\begin{tabular}{|c|c|c|c|c|}
\hline \multirow{2}{*}{$\begin{array}{c}\text { Improvement in the following } \\
\text { particular components of a } \\
\text { transportation facility will } \\
\text { promote public transportation use }\end{array}$} & \multicolumn{4}{|c|}{ Rate in Percentage } \\
\cline { 2 - 5 } & Overall & City & Mountain & Beach \\
\hline Cleanliness & $23.92 \%$ & $23.84 \%$ & $26.00 \%$ & $23.53 \%$ \\
\hline Increased Service & $24.54 \%$ & $24.51 \%$ & $26.00 \%$ & $24.51 \%$ \\
\hline Security & $26.00 \%$ & $26.07 \%$ & $24.00 \%$ & $26.47 \%$ \\
\hline Comfort & $25.53 \%$ & $25.57 \%$ & $24.00 \%$ & $25.49 \%$ \\
\hline
\end{tabular}

Table 3 summarizes results for question on 'what components should be improved in a transportation facility to promote public transportation use'. Overall, the respondents agree that improvement in 'security' of a transportation facility will promote transportation use, as did city and beach respondents. The trend seems to follow where 'cleanliness' is the lowest factor to promote transportation use from the looks of the overall data, city respondents, and beach respondents. A noticeable difference can also be seen for mountain respondents where the data seem to more or less agree for all factors as the percentages are quite similar to each other. 'Cleanliness' and 'increased service' is regarded as the most important component to improve in promoting transportation use with $26 \%$ each, whereas 'security' and 'comfort' is the opposite with $24 \%$ each.

\section{Conclusion}

This paper examines critical demands and conditions according to Indonesian citizens in pursuing integrated urban transportation development based on transportation sustainability indicators in Karawang region in Indonesia. The results show that safety is the most influencing factors in selecting mode of transportation, more reliable service is needed to be improved to attract public transportation users and security is needed to enhance transportation facility to promote public transportation use. Even though there are some low earning rates, this does not indicate that factors (i.e. weather, environmental concerns, and social stigma) which affect alternative decision of transportation are not important. This indicates that Karawang people prefer to have better safety, security and personal comfort for their preference.

The authors would like to acknowledge funding support from Universitas Indonesia through PITTA Grant No. 743/UN2.R3.1/HKP.05.00/2017 for conducting research and disseminating research results. Authors also gratitude the Center for Sustainable Infrastructure Development for the in kind contribution in supporting this research.

\section{References}

1. K. C. Goh, J. Yang, Importance of Sustainability-Related Cost Components in Highway Infrastructure: Perspective of Stakeholders in Australia, J. Infrastruct. Syst. 20, 1 (2014)

2. Y. Latief, M. A. Berawi, A. D. Rarasati, L. S. Supriadi, A. R. B. Berawi, I. S. Hayuningtiyas, Mapping Priorities for The Development of The Transportation 
Infrastructure in The Provincial Capitals of Indonesia, International Journal of Technology 7, 4, pp. 544-552 (2016)

3. M. Fay, M. Toman, D. Benitez, S. Csordas, Infrastructure and Sustainable Development, Postcrisis Growth and Development, The World Bank, pp. 329-372 (2011)

4. A. Sjafruddin, Pembangunan Infrastruktur Transportasi untuk Menunjang Pembangunan Berkelanjutan Berbasis Ilmu Pengetahuan, pp. 1-11 (2011)

5. National Development Planning Agency (Bappenas), Buku I Agenda Pembangunan Nasional (2014)

6. I. G. Malkina-Pykh, Integrated assessment models and response function models: pros and cons for sustainable development indices design, Ecological Indicators 2, 1-2, pp. 93-108 (2002)

7. K. N. Lee, Urban Sustainability and the Limits of Classical Environmentalism, Environment and Urbanization 18, 1, pp. 9-22 (2016)

8. H. P. Egler, R. Frazao, Sustainable Infrastructure and Finance - How to Contribute to a Sustainable Future, pp. 1-41 (2016)

9. A. Bhattacharya, J. Oppenheim, N. Stern, Driving Sustainable Development Through Better Infrastructure: Key Elements of a Transformation Program 91, pp. 1-49 (2015)

10. H. Gudmundsson, Indicators and performance measures for Transportation, Environment and Sustainability in North America, Research Notes 148 (2001)

11. J. W. Creswell, Research Design 4 (2014)

12. U. Sekaran, Research Methods for Business 4 (2003) 